[ RAFAELA NOROGRANDO ]

Mestre em Antropologia Social e Cultural pela Universidade de Coimbra e doutoranda em Design pela Universidade de Aveiro, Portugal. É membro do ICOM (International Council of Museums) e trabalha como investigadora do ID+ Research Institute for Design, Media and Culture.

E-mail: norogrando@gmail.com

\title{
Moda \& museu: instituições, patrimonializações, narrativas
}

\author{
Fashion \& museum: institutions, \\ patrimonializations, narratives
}

[resumo] Trata da relação entre instituição museológica e moda pelos critérios de patrimonialização, e apresenta o panorama de museus temáticos no Brasil e em Portugal. Baseado em revisão bibliográfica, coleta de dados, pesquisa de campo e entrevistas, destaca o ciclo de consagração e defende planejamento e ética.

\section{palavras-chave}

\section{moda; museu; sociedade; patrimonialização;} narrativas.

[abstract] This article is about the relationship between fashion and museum by the patrimonialization criteria, and it presents the panorama of thematic museums in Brazil and Portugal. Based on literature review, data collection, field research and interviews, it highlights the cycle of consecration and defends planning and ethics.

[key words] fashion; museum; society; patrimonialization; narratives. 
Este artigo traz reflexões tecidas no âmbito das relações entre moda, museu e sujeito entrelaçadas pela cultura material e abarcadas pelo corpo social. Tem como base investigação de mestrado em Antropologia Social e Cultural (NOROGRANDO, 2011) que tratou da relação entre Moda e Museu e os critérios adotados em processo de inventário.

Para unir os conceitos de moda e museu, utilizamos a contextualização histórica elaborada no período da Revolução Francesa. Acredita-se ser esse um momento importante para a validação e reutilização de símbolos (GEORGEL, 1994), o que aproxima moda e museu pelo conceito de indivíduo/sociedade e bem comum. A partir desse movimento na capital francesa, o conceito de museu público foi gerido, o que significa que as salas de curiosidades, repletas de relíquias, passam a ser reestruturadas, e outros visitantes, que não somente o clero e os nobres, passam a ter acesso e a conhecer aquelas preciosidades - a partir de então, o patrimônio se torna público.

A moda, que, segundo alguns pesquisadores, inicia seu processo no século XIV (LAVER, 1989; LIPOVETSKY, 1989; BAILLEUX e REMAURY, 1996), emerge neste momento também como símbolo do novo processo de transformação social, assim, a linguagem corporal indumentária se altera, e regras antes rigidamente estabelecidas são derrubadas por decreto de lei (MONNEYRON, 2007). 0 que antes era restrito a alguns passa a ser público, cada cidadão pode usufruir de sua liberdade e igualdade, inclusive na moda.

A relação entre a sociedade e a cultura material sofre uma revisão filosófica e prática. Dessa maneira, os objetos de valor, ou melhor, os objetos de valor simbólico socioeconômico passam a ser reclamados e usufruídos, ainda que de maneira inicial, por uma parcela maior da sociedade. E assim, a ideia de museu público e a de moda (mais próximo do que entendemos hoje) emergem juntas.

No entanto, se analisadas por sua constituição primeira, estas instituições, moda e museu, podem ser percebidas como opostos, principalmente se vistas por uma relação de economia binária. Os museus trazem em sua constituição o conceito de permanência. A indumentária, na sua evolução e contextualização presente, apresenta-se por meio das engrenagens da Moda em uma constante recriação de si mesma, em atuações efêmeras no processo de fazer-se constante. Quando tratamos de moda, falamos de um sistema oriundo em contexto social e nutrido de seus simbolismos específicos (e não nos referimos a períodos anteriores ao século XIV).

Os objetos inseridos no ambiente museológico são destituídos de suas funções práticas; a eles são atribuídos outros valores. Como determina Pomian (1984, p. 54), esses objetos continuam a ter "um valor de troca sem ter valor de uso". Ou seja, em análise de sua evolução empírica na relação contínua com locais que estão fora do contexto diário e mesmo locais de rituais para além da relação cotidiana, os museus, já em sua origem, apresentam-se "fora deste mundo, em tempo e espaço liminares" (BOUQUET e PORTO, 2005, p. 21, tradução nossa).

Entretanto, cada vez mais a museologia crítica questiona e impulsiona movimentos de reestruturação conceitual e prática, forçando as instituições museológicas a se inserir de maneira mais ativa no contexto social. Reinventar-se nas alternâncias das dinâmicas causadas por sujeitos e comunidades, sem perder de vista a sua função social.

(...) a preservação de um aglomerado de bens (tangíveis ou intangíveis) não constitui por si só um patrimônio. É preciso que tanto o remetente quanto o destinatário dessa prática social reconheçam e agreguem valores de uma geração para outra (perspectiva diacrônica), como também poderá ser partilhado numa mesma geração (perspectiva sincrônica). (CHAGAS, 2009, p. 99)

0 conceito de patrimônio também vincula ao conceito de museu a ideia do que seria identidade, "ambos são ficções que veiculam imagens sociais e politicamente negociadas, bem como histórica e culturalmente construídas sobre um determinado colectivo humano [e assim constitui-se em uma] construção cultural", concluem Peralta e Anico (2006, p. 3). 


\section{Órgãos reguladores}

Para Shelton (2001, p. 146, tradução nossa), a "museologia operacional como instituição narrativa incorpora a legitimidade do discurso, envolvendo a atividade de colecionar, o valor e o uso da preservação e disposição de categorias de artefatos de valor, tanto quanto a codificação de práticas e atitudes que constituem seus habitus".

De acordo com os estatutos do ICOM (International Council of Museum), adotado

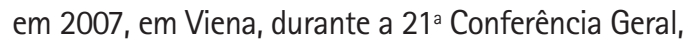

um museu é uma instituição permanente, sem fins lucrativos, ao serviço da sociedade e do seu desenvolvimento, aberta ao público, que adquire, conserva, pesquisa, comunica e expõe o patrimônio material e imaterial da humanidade e seu meio ambiente para fins de educação, estudo e diversão. Esta definição é uma referência na comunidade internacional.

0 ICOM também destaca oito mandamentos, um código de ética, ${ }_{1}^{2}$ que constituem a responsabilidade e razão de ser das instituições museológicas:

1. Os museus preservam, interpretam e promovem o patrimônio natural e cultural da humanidade;

2. Os museus mantêm acervos em benefício da sociedade e de seu desenvolvimento;

3. Os museus mantêm referências primárias para construir e aprofundar conhecimentos;

4. Os museus criam condições para fruição, compreensão e promoção do patrimônio natural e cultural;

5. Os recursos dos museus possibilitam a prestação de outros serviços de interesse público;

6. Os museus trabalham em estreita cooperação com as comunidades das quais provêm seus acervos, assim como com aquelas às quais servem;

7. Os museus funcionam de acordo com a legislação;

8. Os museus atuam com profissionalismo.

0 ICOM é uma organização não governamental criada em 1946. Apresenta relação direta com a UNESCO; em caráter formal, executa parte do seu programa para museus. A organização também possui status consultivo no Conselho Econômico e Social da ONU e apresenta conselhos em diversos paises e regiões. Em julho de 1962,

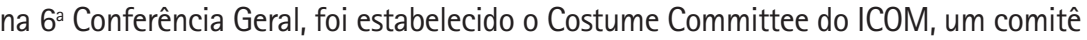
direcionado especificamente à indumentária.

No Brasil, o ICOM-BR foi fundado em 1948, e o órgão governamental que regula as atividades museológicas é o Instituto Brasileiro de Museus (IBRAM), vinculado ao Ministério da Cultura (MinC) e com relação direta com o Sistema Brasileiro de Museus (SBM). Outro órgão importante nesse contexto de cultura patrimonial é o Instituto de Patrimônio Histórico e Artístico Nacional (IPHAN); mais antigo que os anteriores, foi fundado em 1937. Nos sites oficiais, é possivel verificar uma relação de definições anteriormente traçadas em um contexto geral sobre a significação de museu, e em destaque o que é declarado pelos órgãos brasileiros na atualidade:

Os museus são casas que guardam e apresentam sonhos, sentimentos, pensamentos e intuições que ganham corpo através de imagens, cores, sons e formas. Os museus são pontes, portas e janelas que ligam e desligam mundos, tempos, culturas e pessoas diferentes.

Os museus são conceitos e práticas em metamorfose. ${ }^{3}$ 
Em Portugal, há nomeadamente o Instituto dos Museus e da Conservação (IMC), organismo do Ministério da Cultura (M|C), que integrou o Instituto Português de Museus (IPM), o Instituto Português de Conservação e Restauro (IPCR) e a Rede Portuguesa de Museus (RPM). 0 país apresenta também o ICOM-PT, além de associações.

É importante resaltar que algumas nomenclaturas e atuações de órgãos governamentais sofrem alterações com o passar do tempo, ou de mandatos, motivando, muitas vezes, o surgimento de novas siglas e regularizações.

\section{Museus temáticos}

Existem algumas instituições museológicas que trabalham a temática do traje enquanto indumentária e/ou objeto de moda, tais como: Palais Galliera e o Musée de la Mode et du Textile, ambos em Paris, na França, e, no Japão, o Kyoto Costume Institute, para citar os mais renomados. Além destes, e embora não se constituam exclusivamente por essa tipologia, é preciso acrescentar à mesma lista o Victoria and Albert Museum, em Londres, e o Metropolitan Museum of Art de Nova York pelas atuações do departamento The Costume Institute (Cl-MET).

Além destes, e entre outros, algumas instituições vêm ganhando destaque por seu trabalho e acervo, como é o caso do The Museum at FIT de Nova York, o Museo del Traje-CIPE (Centro de Investigación del património Etnológico) de Madri, e, na América Latina, o Museo de la Moda, uma instituição privada no Chile. Esta, além do impressionante acervo, apresenta uma estrutura nos mais altos níveis de exigência de conservação, e as exposições temporárias são massivas, pois há um grande espaço expositivo que possibilita a escolha de muitas peças para compor cada temática das grandes exposições que realizam por ano. Também apresentam a possibilidade de conjugar o objeto com sua reprodução em editorial de moda, graças ao completo acervo bibliográfico de revistas que possuem.

Ainda na América Latina, em Buenos Aires, na Argentina, encontra-se o Museo Nacional de la Historia del Traje, uma instituição pública com intenso programa de atividades e com constantes pesquisas e cadastro virtual do acervo. ${ }^{4}$

No Brasil, infelizmente, as opções expositivas ainda são poucas, estando muitas peças guardadas em armários institucionais, devido a diferentes motivos. Pode-se relacionar aqui as questões de conservação, as quais são difíceis de se manter com objetos tão frágeis ao tempo. Há também as particularidades expositivas que esse tipo de objeto exige: um suporte, pois a roupa requer um corpo para ser percebida, e este foi alterado ao ser vestido pelos tempos da moda. Isso significa um investimento particular para o seu processo de exposição, além de conhecimentos específicos relacionados à natureza do material, às técnicas empregadas e à contextualização desses objetos.

Com relação a acervo patrimonial brasileiro, o Museu Histórico Nacional, no Rio de Janeiro, é detentor de uma significativa coleção na temática de traje/moda. De outubro de 2002 a junho de 2003, fez importante exposição de parte desse patrimônio. Em sua galeria virtual, é possível acessar algumas fotos dessa exposição e do acervo.

Em São Paulo, o Museu Paulista da Universidade de São Paulo (USP) tem feito trabalhos de pesquisa e reprodução de altíssimo rigor científico, nomeadamente o Projeto Replicar. Por meio deste, adquiriu-se maior conhecimento sobre algumas peças e maior possibilidade de contato expositivo. Há também o acervo de moda do Museu de Arte de São Paulo (MASP), não mencionado em seu website. ${ }^{5}$

Em Salvador, pela Fundação Instituto Feminino da Bahia, é possivel visitar a exposição permanente do Museu do Traje e do Têxtil, uma iniciativa pioneira de exposição museológica permanente no Brasil.

Todos acima referidos estão no extenso Guia dos Museus Brasileiros divulgado pelo IBRAM/Ministério da Cultura, ${ }^{6}$ no qual encontramos ainda o Museu Décio Magalhães Mascarenhas, em Minas Gerais, criado e mantido pela empresa Cedro Têxtil, e a Fundação Museu Mariano Procópio, em Juiz de Fora (MG), com trajes de Dom Pedro II e da Princesa Isabel. Embora tenhamos uma extensa listagem, é dificil identificar quais instituições apresentam coleções de moda, o que requer uma investigação mais detalhada. Tal compilação, seja das instituições, seja dos objetos de suas coleções temáticas, seria de grande valia para estudos e pesquisas na área. $\mathrm{Na}$ Europa isto é feito pela "europeana fashion", iniciativa criada para agrupar este patrimônio em uma plataforma virtual. 
No mesmo guia do IBRAM/MinC, há também outros museus dedicados a temáticas específicas, alguns já cadastrados e outros somente mapeados - no Rio Grande do Sul, estão o Museu Nacional do Calçado, em Novo Hamburgo, e o Museu do Sapato, em Gramado, e, em Belo Horizonte (MG), o Museu do Bordado. Há ainda os museus mais temáticos, focados em personalidade ou evento (local/nacional), tais como o Museu Carmen Miranda, o Museu do Carnaval e o Centro de Memória do Carnaval. Localizados na cidade do Rio de Janeiro, apresentam um acervo muito mais direcionado a figurino. Pela mesma lista é possivel localizar, em Blumenau (SC), o Museu do Têxtil e da Moda da Universidade Regional de Blumenau.

No contexto virtual, e não mapeados nessa edição do IBRAM, o Brasil possui o MIMO - Museu da Indumentária e da Moda, abarcado pela Universidade Anhembi Morumbi e constituído como Grupo de Pesquisa do Diretório do CNPq, que se encontra num fervoroso processo de consolidação. Além deste, pode-se conseguir algumas informações em rede com o Museu do Calçado de Franca, da UNIFRAN, e ainda, não se declarando como museu, o website Sapatos Online, vinculado à rede desde janeiro de 2000 apresenta informações direcionadas a esse segmento, com destaque para as questões de conservação, natureza da empresa provedora do site.

Inaugurado em dezembro de 2011, em Gramado (RS), o MUM - Museu da Moda é um projeto de iniciativa particular. Conforme divulgações e entrevista, é constituído por produções de arquétipos da história da indumentária e da moda em uma extensa linha cronológica.?

Por fim, na cidade do Rio de Janeiro, existe o projeto para a consolidação do Museu da Moda, que ocupará o Solar da Marquesa de Santos, um casarão do século XIX, no bairro de São Cristovão, tombado desde 1938, e atualmente em reforma e restauração. 0 Museu da Moda terá um acervo permanente e salas para exposições temporárias, porém, a data de abertura ainda é incerta.

Em ligação direta com a história da indumentária e da moda no Brasil, é importante citar o contexto museológico português, ${ }^{8}$ dado que é com a chegada da Corte ao Brasil que grandes transformações ocorrem no país, inclusive no que diz respeito aos modos e modas dos brasileiros.

Dito isso, apresenta-se o Museu Nacional do Traje, em Lisboa, na região do Lumiar, com mais de 40.000 objetos e quase 35 anos de atuação. Esse museu apresenta em seu acervo patrimonial uma importante coleção de traje do Império, roupas intimas de diferentes períodos, botões e adereços, entre outros. Além disso, estão lá os trajes que ficaram no porto de Lisboa, esquecidos na rápida partida da corte portuguesa para o Brasil. Esta, quando regressou, manteve essas roupas fora de uso, pois os anos no pais foram suficientes para que essas peças ficassem fora de moda.

Para além desse museu, foi inaugurado, em maio de 2009, o MUDE - Museu do Design e da Moda. A designação MUDE não é formada como sigla, mas como palavra de ação - o verbo mudar no modo imperativo, conforme esclareceu a diretora Bárbara Coutinho em entrevista. ${ }^{9}$ Em outubro de 2011, abre ao público, pela primeira vez, todos os seus andares/salas de exposição de maneira ativa, além de sediar o MUSCON ${ }^{10}$ e receber os participantes do CIPED"1 em sua primeira versão fora do Brasil.

Ainda na região sul de Portugal, há o Museu do Trajo de São Brás de Aportel e o novissimo Museu do Artesanato e do Design (MADE), inaugurado em novembro de 2011 na cidade de Évora. Ao norte, com um foco bastante etnográfico, encontra-se 0 Museu do Traje, em Viana do Castelo, e o ainda mais temático Museu da Chapelaria, em São João da Madeira. Este foi instalado em uma antiga fábrica e está dedicado, para além do objeto, à identidade local e de trabalhadores do ramo. A região é muito forte no setor calçadista; entretanto, o museu do calçado ainda é um projeto.

Entre essas atuais instituições, estão também a somar mais museus, galerias ou centros culturais dedicados ao traje, à moda ou aos acessórios. Ou ainda, dedicados a profissionais/personalidades/marcas do ramo; constituem o que Belk (1995) qualifica como museus corporativos. Como exemplo disso no Brasil, existe, em Blumenau, o Museu Hering, da mais que centenária companhia brasileira, conhecida inicialmente 
por suas camisetas brancas de malharia circular. A empresa, com mais de 130 anos, apresenta no museu sua história, a memória local e, inevitavelmente, a história da indústria de moda brasileira. Por sua representatividade na identidade da região, no estado catarinense e no mercado nacional, deve-se considerar como um ganho para o contexto brasileiro a iniciativa desse projeto inaugurado em novembro de 2010.

Acredita-se que a tendência é de que haja cada vez mais museus, conforme já é possível verificar pela "explosão museológica" iniciada na segunda metade do século XX (GARCIA, 2003) e a "atual obsessão com a memória" (VILLAÇA, 2010, p. 124). Ou ainda, como acontece na Alemanha, o termo museu não está oficialmente definido, resultando num número elevado de instituições assim intituladas no país e com as mais diversas temáticas, conforme esclarece o Institut für Museumskunde (GARCIA, 2003). No Brasil, é possível verificar uma situação relativamente similar. A listagem feita pelo IBRAM/MinC foi uma iniciativa relevante para o conhecimento dos "museus" existentes no Brasil, no entanto alerta-se que uma segunda avaliação deve ser feita, de preferência pelo órgão responsável, quanto à realidade de atuação dessas instituições para que não haja confusão e desgaste na busca por informações patrimoniais.

A presença da palavra museu constitui um valor percebido devido a sua significação por contextos históricos e imaginário social, e ainda, diante do sistema da moda, entram em sinergia por "circuito de consagração" (BOURDIEU, 2011), cada império conferindo ao outro valorização e status.

A escolha pela nomenclatura institucional é fortemente atraída pelo posicionamento e missão a que esta se propõe, e isso é dado por contextos e interesses diversos, por escolha discursiva, conforme defendem Shelton (2006), Sherman e Rogoff (1994) e Viana (2006). É possível perceber pelos próprios nomes institucionais aqui listados que existem diferenças nos seus posicionamentos já em suas designações, por exemplo: traje, moda, indumentária, têxtil etc. Se verificarmos a missão de cada um, também encontraremos particularidades, e são estas que nortearão seus processos e atividades perante o público e as comunidades envolvidas com a instituição ou com a temática de seu acervo. Algumas carregam em sua nomenclatura o peso estatal, são instituições que, declaradas "nacionais", carregam a utópica atribuição de representar a todos, ou, como em alguns casos, o termo não é assumido por significação ou prática, mas por sua posição burocrática, legal, ou ainda, como atributo de valor.

\section{Objeto de uso a objeto patrimonial}

Com essa contextualização, seguimos a exposição dos critérios de patrimonialização, ou seja, quais atributos os museus consideram adequados para um objeto ser considerado para integrar o acervo patrimonial preservado por eles como instituições regularizadas. É importante ressaltar que esta pesquisa considerou como foco os objetos indumentários oriundos do contexto contemporâneo.

Em estudo, foram primeiramente levantadas informações dos seguintes museus: Museu Nacional do Traje (MNT, PT), Museu do Design e da Moda (MUDE, PT), Museo del Traje-CIPE (MT-CIPE, ES), The Museum at FIT (M-FIT, USA), Victoria and Albert Museum (V\&AM, RU), Mode Museum Provincie Antwerpen (MoMu, Bélgica). Para 0 levantamento dos critérios adotados no processo de inventário dessas instituições, considerou-se informações coletadas nos sites oficiais e outras publicações, ou entrevistas, e a pesquisa de campo foi realizada em alguns casos.

Em uma segunda fase, a verificação das informações se deu nas seguintes instituições: Museu Tèxtil i d'Indumentària (DHUB-MTI, ES), Museo Nacional de la Historia del Traje (MNHT, AR) e Museo de la Moda (MM, CL). Em todos, os dados foram levantados por registros institucionais, pesquisa de campo e entrevistas.

Para este artigo, apresenta-se o resumo sucinto dos resultados obtidos e a reflexão gerada já na primeira fase da pesquisa. A segunda fase prossegue com outro direcionamento $^{12}$ e informações; para a questão aqui levantada, apresentou confirmações.

Algumas ações são contantes, tal como o recebimento de doações por parte de industriais, colecionadores ou, na maior parte das vezes, de particulares. Alguns dos museus pesquisados apresentam essa iniciativa como única forma de acréscimo ao acervo. Outros, com mais recursos financeiros, podem adotar estratégias mais ativas na busca de peças. Ou ainda, há a possibilidade, muito bem trabalhada por alguns, de parcerias e 
projetos de memória integrados com outras instituições (públicas ou privadas). Entretanto, seja por uma maneira, seja por outra, as peças que são adquiridas pela instituição museológica costumam seguir a missão a que esta se propõe, sua razão institucional; dessa maneira, mesmo que por doação, as peças são avaliadas e o aceite ou não das mesmas segue alguns critérios - dentre estes listamos e explicamos os que foram averiguados.

Por unanimidade, o critério de totalidade é um dos primeiros a ser considerado. Significa a busca de peças que supram lacunas na coleção patrimonial existente, na abrangência a que a missão do museu se propuser. Outro atributo muito considerado dos objetos é o valor por historicidade; estão classificados os anteriores ao século $X X$. Até aqui, pode-se perfeitamente dizer que são critérios comuns para a grande maioria das instituições museológicas ou colecionadores: ter uma coleção completa e alargada por uma linha cronológica.

Outro critério adotado por essas instituições, por unanimidade, mas não como foco primordial de todas, está na relevância dada a peças oriundas de personalidades e autor/marca consagrada no sistema da moda. Se unir as duas celebridades, tanto melhor.

Também muito forte para alguns dos museus estudados é a questão de valorizar o design autoral/marca de vanguarda, e a isso alguns ressalvam os que apresentam altíssima qualidade técnica.

Uma atitude relativamente recente para com os critérios está na valorização de peças consagradas na rua e pela cultura jovem, ou seja, o que for mais vendido e acabar por simbolizar um dado período ou grupo representativo no cenário social urbano. Há ainda, para instituições ligadas fortemente, por parcerias, a instituições de ensino, a inclusão de trabalhos acadêmicos (excelentemente bem avaliados) no acervo patrimonial, e aí estariam abarcados não somente peças confeccionadas de traje, mas o processo criativo de tal elaboração.

Por fim, na opinião muito pontual de um pensamento de perspectiva futura da história da moda (algo sempre ariscado de se fazer, mas um bom exercício), há a declaração de valorizar a inovação e a tecnologia têxtil. Assim, a curadora e conservadora Silvia Ventosa, ${ }^{13}$ do DHUB-MTI, declara um direcionamento em perceber a tecnologia têxtil empregada às peças de vestuário, e não tanto as formas que estas apresentam.

Com base nisso, e não tendo sido declarado por nenhuma, acredita-se que a questão da sustentabilidade venha a fazer parte das análises futuras sobre os objetos do sistema da moda. Essa é uma questão latente no processo produtivo e ético do sistema, pois este apresenta uma proporção global, e atitudes começam a ser efetivamente adotadas por consumidores, produtores e outros agentes. No contexto museológico da temática da moda, o assunto é abordado pelo V\&A em seu website.

Em resumo, a valorização da totalidade, da historicidade e de peças de marcas consagradas no cenário da moda são a tônica para a análise de valor das coleções que essas instituições detêm e, consequentemente, seu estatuto perante as outras, sendo também consideradas as condições de conservação e pesquisa.

Na linha de atuação da cultura material, ou seja, dos objetos construidos culturalmente por sociedades, coloca-se o Império do Perene em um extremo e o Império do Efêmero em outro. Sendo possível perceber que essa linha entre um e outro pode ser mais longínqua, ou mais estreita. Museu e moda, embora distantes pela análise de suas intenções imediatas: perpetuar $X$ renovar; valorizar culturalmente $X$ valorizar economicamente; preservar $X$ usar; estão próximos quando percebe-se que ambos sobrevivem de matéria sagrada, de objetos munidos de simbolismo. 0 ato de sacralizar objetos aproxima esses dois extremos, pois ambos alimentam-se desse simbolismo para ativar sua existência. (NOROGRANDO, 2011, p. 84) 


\section{Considerações finais}

A cultura material, a imagem e a mídia, a imaginação, o espectáculo e a sacralização, além do consumo, são facetas que caracterizam a sociedade contemporânea em suas teias territoriais ou virtuais. "Moda e museu estão ambos sempre em adaptação e reestruturação perante o corpo social que os constrói e institui" (NOROGRANDO, 2011, p. 89). Por isso, acredita-se ser importante a transparência do papel e atuação das instituições para "criar uma compreensão mais profunda da especificidade de uma humanidade inseparável de sua materialidade" (MILLER, 2011). Pode-se também dizer que é relevante para a razão de ser dessas instituições as atividades parceiras com as comunidades envolvidas, sejam visitantes, pesquisadores, órgãos públicos e privados de maneira ética.

Sem o intuito de promover o conhecimento sobre o acervo, sua materialidade ou subjetividade, a instituição perde seu conceito. Por esse motivo, os critérios adotados no processo de inventário são as ferramentas cruciais na análise do que possui valor patrimonial. É com esses critérios, na linha da missão de cada instituição, que os objetos são avaliados para serem patrimonializados, ou mesmo destituídos desse valor. Além disso, é com base nessa linha de atuação, vinculada a outros critérios, que o acervo será exposto, e somente essa ínfima parte de patrimônio terá visibilidade pública. É com esse conjunto de definições e conceitos que o posicionamento institucional é percebido e se consolida perante seus pares e o corpo social.

É "mediante essa selecção significativa [que] pretendemos mostrar e enaltecer uma imagem precisa do 'nós' que consideramos valiosa" (TORRICO, 2006, p. 21). Assim, justifica-se a importância de constantes pesquisas e atividades multidisciplinares a traçar narrativas, que, nessa conjuntura, tornam-se memórias patrimoniais. 


\section{NOTAS}

[1] Disponivel em: <http://icom.museum>. Acesso em: 10 set. 2010.

${ }^{[2]}$ Disponivel em: <http://www.icom.org.br/codigo_de_etica_lusofono_iii_2009.pdf >. Acesso em: 10 nov. 2011.

${ }^{[3]}$ Disponivel em: <http://www.museus.gov.br/sbm/oqueemuseu_apresentacao.htm>. Acesso em: 12 nov. 2011.

${ }^{[4]}$ De acordo com a diretora Rosa Iglesias e a coordenadora geral Bárbara Brizzi, em entrevista realizada em agosto de 2011, uma importante coleção de referências de modelagem está sendo digitalizada.

${ }^{[5]}$ Para mais informações sobre a formação desse acervo é aconselhável entrar em contato com o MASP.

${ }^{[6]}$ Disponivel em: <http://www.museus.gov.br/noticias/guia-dos-museus-brasileiros>. Acesso em: 10 nov. 2011.

[7] Entrevista com a idealizadora do projeto, a estilista Milka Wolff. Disponivel em: <http://zerohora. clicrbs.com.br/rs/vida-e-estilo/donna/noticia/2011/04/pecas-da-moda-para-a-historia-3268425.html>. Acesso em: 15 fev. 2012.

${ }^{[8]} 2012$ - Ano Brasil-Portugal. A cidade de Guimarães, Capital Europeia da Cultura 2012, localizada ao norte de Portugal, receberá o CIMODE - $1^{\circ}$ Congresso Internacional de Moda e Design, nos dias 5, 6 e 7 de novembro de 2012. Esse evento é uma parceria entre a ABEPEM e a Universidade do Minho.

${ }^{[9]}$ Entrevista concedida a Rafaela Norogrando. Lisboa, 30 jul. 2010.

${ }^{\text {[10] }}$ European Museum Network Conference - MUSCON 2011. Realizado entre 19 e 22 de outubro de 2011.

${ }^{[11]} 6^{\circ}$ Congresso Internacional de Pesquisa em Design, organizado pela ANPEN Design e o Centro de Investigação de Arquitetura, Urbanismo e Design da Universidade Técnica de Lisboa.

[12] "Exposiç̃es museológicas e objetos de design. A moda por narrativas, experiências e conexões", pesquisa vinculada ao programa doutoral em design (Universidade de Aveiro), sob a orientação dos professores João Mota (UAveiro) e Nuno Porto (UCoimbra). Financiado pela Fundação para Ciência e Tecnologia (PT-EU)

${ }^{[13]}$ Entrevista concedida a Rafaela Norogrando. Barcelona, 26 maio 2011.

\section{REFERÊNCIAS}

BAILLEUX, Nathalie; REMAURY, Bruno. La Moda: usi e costumi del vestire. Triestre: Electa/ Gallimard, 1996.

BELK, Russel W. Collecting in a consumer society. Londres: Routledge, 1995.

BOUQUET, Mary; PORTO, Nuno. Science, magic and religion: the ritual processes of museum magic. Oxford: Berghahn Books, 2005.

BOURDIEU, Pierre. Alta costura e alta cultura. Disponivel em: <http://www.mom.arq.ufmg.br/ babel/textos/bourdieu-alta-costura.pdf>. Acesso em: 24 jan. 2011.

CHAGAS, Mário. 0 pai de Macunaíma e o patrimônio espiritual. In: Memória e patrimônio: ensaios contemporâneos. Rio de Janeiro: Lamparina, 2009.

GARCIA, Nuno Guina. 0 museu entre a cultura e o mercado: um equilíbrio instável. Coimbra: IPC, 2003.

GEORGEL, Chantal. The museum as metaphor in nineteenth-century France. In: SHERMAN, Daniel; ROGOFF, Irit. Museum culture: histories, discourses, spectacles. Londres: Routledge, 1994, p. 113-122.

LAVER, James. A roupa e a moda: uma história concisa. São Paulo: Companhia das Letras, 1989.

LIPOVETSKY, Gilles. 0 império do efêmero: a moda e seu destino nas sociedades modernas. São Paulo: Companhia das Letras. Original, 1989.

MILLER, Daniel. Consumo como cultura material. Disponível em: <http://www.scielo.br/pdf/ha/ v13n28/a03v1328.pdf>. Acesso em: 24 jan. 2011.

MONNEYRON, Frédéric. A moda e seus desafios: 50 questões fundamentais. São Paulo: Senac, 2007.

NOROGRANDO, Rafaela. Como é formado o patrimônio cultural: estudo museológico em Portugal na temática traje/moda. Coimbra, 2011. Dissertação (Mestrado em Antropologia Social e Cultural) - Departamento de Ciências da Vida, Universidade de Coimbra.

PERALTA, Elsa; ANICO, Marta (Org.). Patrimónios e identidades: ficções contemporâneas. Oeiras: Celta, 2006.

POMIAN, Krzysztof. Colecção. Enciclopédia Einaudi. Porto: Imprensa Nacional/Casa da Moeda, 1984, p. 51-86.

SHELTON, Anthony Alan. Unsettling the meaning: critical museology, art and anthropological discourses. In: BOUQUET, Mary. Academic anthropology and the museum: back to the future. Oxford: Berghahn Books, 2001. 
Museums and anthropologies: practices and narratives. In: MACDONALD, Sharon. A companion to museum studies. Oxford: Blackwell, 2006, p. 64-80.

SHERMAN, Daniel J.; ROGOFF, Irit. Museum culture: histories, discourses, spectacles. Londres: Routledge, 1994.

TORRICO, Juan Agudo. Patrimónios e discursos identitários. In: PERALTA, Elsa; ANICO, Marta (Org.). Patrimónios e identidades: ficções contemporâneas. Oeiras: Celta, 2006.

VIANA, Luis Díaz G. 0 património cultural ou os consumos da nostalgia: cultura material e imaterial nos passeios turísticos pela identidade. In: PERALTA, Elsa; ANICO, Marta (Org.) Patrimónios e identidades: ficções contemporâneas. Oeiras: Celta, 2006.

VILLAÇA, Nízia. Mixologias: comunicação e o consumo da cultura. São Paulo: Estação das Letras e Cores, 2010.

\section{WEBSITES}

DHUB-Museu Tèxtil i d'Indumentària: http://www.dhub-bcn.cat/museus/museu-textil-i-dindumentaria Europeana Fashion: http://www.europeanafashion.eu/

Fundação Museu Mariano Procópio: http://www.pjf.mg.gov.br/mapro/museu/historico.php IBRAM/MinC: http://www.museus.gov.br

ICOM: http://icom.museum

ICOM Costume Committee: http://www.costume-committee.org

IPHAN: http://portal.iphan.gov.br/portal/montarPaginalnicial.do

MASP - Museu de Arte de São Paulo Assis Chateaubriand: http://masp.art.br/masp2010

MIMO - Museu da Indumentária e da Moda: http://www.mimo.org.br

MoMu: http://www.momu.be

MUDE - Museu do Design e da Moda: http://www.mude.pt

Museo de la Moda: http://www.museodelamoda.cl

Museo del Traje CIPE: http://museodeltraje.mcu.es

Museo Nacional de la Historia del Traje: http://www.funmuseodeltraje.com.ar

Museu Décio Magalhães Mascarenhas: http://www.cedro.com.br/br/institucional/museu.asp

Museu do Calçado de Franca: http://www.museudocalcado.com.br/inclnternas.

php?page=textoshistoriacalcado/historiacalcado38.htmlEtmenu=hist_Artigos.php

Museu do Traje e do Têxtil - Fundação Instituto Feminino da Bahia: http://www.institutofeminino. org.br/home/index.php

Museu do Trajo de S. B. A.: http://www.museu-sbras.com/index.html

Museu Hering: http://www.ciahering.com.br/site/pt-br/Empresa/Museu+Hering

Museu Histórico Nacional: http://www.museuhistoriconacional.com.br

Museu Nacional do Traje: http://museudotraje.imc-ip.pt

Museu Paulista (Projeto Replicar): http://www.mp.usp.br/replicar/index.html

Sapatos Online: http://www.sapatosonline.com.br

Sistema Brasileiro de Museus: http://www.museus.gov.br/SBM

The Museum at FIT: http://fitnyc.edu/3662.asp

Victoria and Albert Museum: http://www.vam.ac.uk 